\title{
The Expression of p63 Protein in Different Grades of Oral Squamous Cell Carcinoma- An Immunohistochemical Study
}

\author{
A. Dayakar ${ }^{1}$, P. Shetty2 , M.M. Dayakar³ \\ ${ }^{1} \mathrm{PhD}$ Scholar, Department of Oral Pathology and Microbiology, A. B. Shetty Memorial Institute of Dental Sciences, Nitte \\ University, Mangalore, Karnataka, India. ${ }^{2}$ Department of Oral Pathology and Microbiology, A. B. Shetty Memorial \\ Institute of Dental Sciences, Nitte University, Mangalore, Karnataka, India. ${ }^{3}$ Department of Periodontics, KVG Dental \\ College and Hospital, Sullia, Karnataka, India.
}

\section{ABSTRACT}

\section{BACKGROUND}

Oral squamous cell carcinoma is one of the leading cancers throughout the world, especially in the developing countries. Head and neck cancer leads to considerable morbidity and mortality. p63 protein is a promising marker in the study of oral squamous cell carcinoma because of its diverse role in tumour suppression as well as its oncogenic properties. In this study, we have evaluated the qualitative and quantitative p63 expression in different grades of oral squamous cell carcinoma using immunohistochemistry.

\section{METHODS}

52 cases of OSCC were subjected to immunohistochemistry with p63 primary antibody. The intensity of staining as well as the percentage of cells stained was evaluated. Immunohistochemical expression of p63 in different grades of OSCC was studied.

\section{RESULTS}

Highly significant association was observed between intensity of p63 and different grades of OSCC. Percentage of cells stained for p63 and different grades of OSCC showed a very highly significant association. There was a very highly significant association between Immunoreactive score for p63 staining in different grades of OSCC.

\section{CONCLUSIONS}

p63 is a useful marker in the context of oral cancer diagnosis and management. p63 can help in determining the tumour behaviour in different grades of oral squamous cell carcinoma.

\section{KEY WORDS}

p63, Oral Squamous Cell Carcinoma, Immunohistochemistry, Stem Cell, Tumour Suppression, WDSCC (Well-Differentiated Squamous Cell Carcinoma), MDSCC (Moderately Differentiated Squamous Cell Carcinoma), PDSCC (Poorly Differentiated Squamous Cell Carcinoma)

\section{Corresponding Author:}

Dr. Anitha Dayakar,

KVG Dental College and Hospital,

Sullia-574327, Dakshina Kannada,

Karnataka, India.

E-mail: anithadayakar99@gmail.com

DOI: $10.14260 /$ jemds/2019/723

Financial or Other Competing Interests: None.

How to Cite This Article:

Dayakar A, Shetty P, Dayakar MM. The expression of $p 63$ protein in different grades of oral squamous cell carcinomaan immunohistochemical study. J. Evolution Med. Dent. Sci. 2019;8(44): 3332-3336, DOI:
Submission 12-08-2019,

Peer Review 17-10-2019,

Acceptance 23-10-2019,

Published 04-11-2019. 


\section{BACKGROUND}

Oral squamous cell carcinoma (OSCC) is the sixth most commonly observed cancer throughout the world and India harbours the highest incidence of oral cancer. ${ }^{1}$ OSCC is responsible for almost $4 \%$ of the total cancers. The scenario in the developing countries is worse, the prevalence of OSCC is higher, being almost $50 \%$ of all cancers. ${ }^{2}$ Although, advanced therapeutic modalities have evolved, there is only marginal improvement in the survival rate which continues to remain approximately $50 \%{ }^{3}$ Development of OSCC is a continuous multi-stage process involving the cumulative effect of mutation in genes responsible for tumour suppression, cellular proliferation and cell differentiation. ${ }^{4}$ Tumour biomarkers are molecules produced either by the tumour or surrounding host tissue in response to tumourigenesis which have various clinical applications that include risk assessment, diagnosis and staging of cancer prognostication and therapeutic selection. 5

p63 gene, which is located on chromosome $3 q 27-29$, has been regarded as a novel basal cell IHC marker. ${ }^{4} \mathrm{~A}$ dual role of $\mathrm{p} 63$ protein has been reported in both tumour suppression and oncogenesis. p63 protein is expressed in the proliferative layer of cells near the basement membrane of normal oral mucosa, where it prevents basal cells from differentiation and helps to maintain their basal cell status. However, upon dysplastic change, the dysplastic keratinocytes above basal layer can shift to a status similar to embryogenesis conditions and are still able to express p63 protein, which produces an anti-differentiation effect as well as a proliferative capacity of dysplastic cells in the oral dysplastic mucosa. ${ }^{6}$ Expression of p63 protein and mRNA has been observed in various human tumours, including OSCC. It is a consequence of gene amplification. ${ }^{7}$ p63 has an important role to play in the morphogenesis of epithelium derived structures like oral mucosa, salivary glands and dental structures ${ }^{8,9} . \Delta \mathrm{Np} 63$ is considered as a stem cell marker for keratinocytes and p63 expression is restricted to the basal and parabasal strata in the normal mucosa of the oral cavity. ${ }^{10,11}$

As a result of alternative splicing in the molecular structure and the presence of two different promoters, different isoforms of p63 have been identified. These include TAp63 $\alpha$, TAp63 $\beta$, TAp63 $\gamma, \Delta \mathrm{Np} 63 \alpha, \Delta \mathrm{p} 63 \beta$, and $\Delta \mathrm{p} 63 \gamma .{ }^{12}$ It has been postulated that the TAp63 isoforms have a role in tumour suppression, while the $\Delta \mathrm{Np} 63$ isoforms behave like oncogenes. ${ }^{13,14}$ p63 shows homology in structure and function with regard to p53 family. p63 has the capacity to bind with DNA and cause transactivation of p53 downstream targets. ${ }^{15} \quad \Delta \mathrm{Np} 63$ isoforms potentially suppress transactivation of p53 target genes such as p21 which induces apoptosis.

We wanted to study the Immunohistochemical staining pattern with p63 marker protein in different histological grades of oral squamous cell carcinoma and study the correlation of p63 immunohistochemical expression and histopathological grading in oral squamous cell carcinoma.

\section{METHODS}

This is a retrospective observational study. Oral squamous cell carcinoma biopsy cases reported at Department of Oral Pathology, A.B. Shetty Memorial Institute of Dental Sciences, Mangalore, India during the period from January 2014December 2016 were selected for the study. Cases of any other malignancy in the oral cavity or extraoral sites, patients who had undergone radiotherapy or chemotherapy, recurrent oral cancer cases were excluded from the study.

Ethical clearance for the study was obtained from the Institutional Ethical committee, NITTE University. $\mathrm{H}$ and $\mathrm{E}$ stained slides of selected cases were examined, the diagnosis was confirmed, and the blocks were retrieved from the archives. All the slides were methodically evaluated by two different observers (AD, PS) so as to rule out inter observer bias. The $\mathrm{H}$ and $\mathrm{E}$ slides were evaluated and graded according to WHO 2005 system. ${ }^{16}$

Squamous cell carcinoma cases were of well differentiated/ moderately differentiated/ poorly differentiated squamous cell carcinoma. Clinical details of the patients including habits, size of the lesion, lymph node status, and staging were noted. Also, 6 cases of normal uninflamed mucosa subjected to immunohistochemistry served as control.

p63 expression was determined using monoclonal antibodies and MACH 4 Universal HRP Polymer Detection System (Biocare Medical, CA, USA). The p63 antibody used was p63 (4A4) concentrated mouse monoclonal antibody. The p63 concentrated antibody was diluted at 1: 100 dilutions with Van Gogh Yellow diluent. $4 \mu \mathrm{m}$ sections of the selected cases were obtained on poly $\mathrm{L}$ silane coated slides. The sections were then incubated at $70^{\circ} \mathrm{C}$ for 20 minutes. The sections were then deparaffinized with 2 changes of xylene for 10 minutes each. Later, the slides were dipped in two changes of absolute alcohol for 5 minutes each followed by $95 \%$ alcohol for 3 minutes. The slides were immersed in EDTA antigen retrieval solution ( $\mathrm{pH}$ 8.5) and antigen retrieval was done with the pressure cooker method. The slides were then washed with TRIS Buffer saline solution. The slides were dried, blotted gently and placed in humid chamber. Endogenous peroxidase was blocked by treating with 3\% hydrogen peroxide for 5 minutes. The slides were then washed with TBS buffer. The sections were treated with Protein block for 10 minutes to prevent nonspecific staining. Sections were incubated with p63 Monoclonal Mouse Antibody for 30 minutes. The sections were then rinsed with 2 washes in TBS. Sections were then incubated with Mouse probe secondary antibody for 10 minutes. Slides were rinsed in TRIS wash buffer. The sections were incubated with MACH 4 HRP- Polymer for 20 minutes. The DAB substrate solution was added to the sections and kept for 5 minutes. The sections were counterstained with Harris Haematoxylin and mounted with DPX. Sections with omission of primary antibody served as negative controls.

\section{Immunohistochemical Analysis}

The slides were viewed in a bright field microscope for analysing the intensity and pattern of staining. Since p63 is a nuclear marker, nuclear staining was taken as positive. All the slides were methodically scanned, evaluated by two 
observers independently (AD, PS) and the evaluations were repeated by each observer to remove interobserver bias.

The photomicrographs for assessing the percentages of positive cells were taken at $40 \mathrm{X}$ magnification using Motic Microscope Camera attachment. 10 representative areas were randomly selected for quantitative analysis. In normal mucosa control slides, the epithelium containing areas were selected. In squamous cell carcinoma slides, areas were selected from invasive tumour island areas. The epithelial cells were counted using Image Analyser. The percentage of p63 expression was calculated by determining the number of positive cells expressing p63 staining among the total number of epithelial cells in a selected area. An average of the 10 readings was taken as the final score.

Percentage of positive cells $=$ Number of positive cells in an area $\mathrm{x} 100$ / Total number of epithelial cells in the area

Percentage of positive cells was graded as

0 - No positive cells.

1- $1 \%$ to $25 \%$ positive cells.

2- $25 \%-50 \%$ positive cells.

3- $50 \%-75 \%$ positive cells.

$4-\quad>75 \%$ positive cells.

Staining intensity was graded as-

0 - No colour reaction.

1- Mild reaction.

2- Moderate Reaction.

3- Intense Reaction.

The final immunoreactive score IRS represented the product of both the values, intensity and percentage of cells stained, ranging from $0-12$ points as ${ }^{5}$

0 to 1 - Negative,

2 to 3 - Positive weak expression,

4 to 8 - Positive mild expression,

9 to 12 - Positive, strong expression.

\section{Statistical Analysis}

The data collected was recorded into Microsoft Excel Spread sheets. This data was then evaluated using SPSS Version 22.0 software. Data analysis was done using Chi square test.

\section{RESULTS}

The study sample consisted of the 52 cases of OSCC and 6 normal mucosa controls. Further, among oral squamous cell carcinoma cases, 25 cases were WDSCC, 20 cases were MDSCC, 7 cases were PDSCC. 6 cases were of normal mucosa serving as control. In our study, all cases of well differentiated and moderately differentiated squamous cell carcinoma were positive for $\mathrm{p} 63$. In case of poorly differentiated carcinoma, 2 cases showed negativity for p63 marker, the rest were positive.

Clinical history of cases selected for the study was retrieved. The age range was from 38 years to 75-year-old patients. Of the 52 patients whose clinical history was examined, 39 were males, while 13 patients were females. It shows a trend towards younger patients getting affected by oral cancer. Also, chewing Tobacco with/without arecanut/lime/betel leaves is noted as common habit among the coastal Karnataka and Kerala patient population. Chewing habit was seen in total 36 patients ( 23 male, 13 female).Thus, tobacco chewing was the common predominant risk factor in all female patients. Gutka chewing was seen in 4 patients. 8 male patients gave history of smoking with/without tobacco chewing, out of which 5 patients had only smoking habit. Use of alcohol was elicited from 11 patients. 5 of the patients had a previous history of oral submucous fibrosis (OSMF) with subsequent malignant transformation. All 5 OSMF patients had a history of chewing tobacco with arecanut, and all 5 cases occurred on right side of the oral cavity ( 3 buccal mucosa and 2 cases on the alveolar ridge).

\begin{tabular}{|c|c|c|c|c|c|c|}
\hline & \multicolumn{5}{|c|}{ Intensity of Staining } & \\
\hline Grade & $\mathbf{0}$ & 1 & 2 & 3 & Total & \multirow{6}{*}{$\begin{array}{c}x^{2}=25.184 \\
p=0.003 \\
\text { Highly } \\
\text { significant. }\end{array}$} \\
\hline WDSCC & $0(0 \%)$ & $1(4 \%)$ & $11(44 \%)$ & $13(52 \%)$ & 25 & \\
\hline MDSCC & $0(0 \%)$ & $0(0 \%)$ & $5(25 \%)$ & $15(75 \%)$ & 20 & \\
\hline PDSCC & $2(28.6 \%)$ & $1(14.3 \%)$ & $1(14.3 \%)$ & $3(42.9 \%)$ & 7 & \\
\hline Normal mucosa & $0(0) \%$ & $1(16.7 \%)$ & $4(66.7 \%)$ & $1(16.7 \%)$ & 6 & \\
\hline Total & 2 & 3 & 21 & 32 & 58 & \\
\hline
\end{tabular}
Grade of Squamous Cell Carcinoma

\begin{tabular}{|c|c|c|c|c|c|c|c|}
\hline & & \multicolumn{5}{|c|}{ Percentage of p63-Positive Cells } & \\
\hline Grade & $\mathbf{0}$ & 1 & 2 & 3 & 4 & Total & \multirow{6}{*}{$\begin{array}{c}x^{2}= \\
38.921 \\
p<0.001 \\
\text { Very } \\
\text { Highly } \\
\text { significant }\end{array}$} \\
\hline WDSCC & $0(0 \%)$ & $4(16 \%)$ & $12(48 \%)$ & $8(32 \%)$ & $1(4 \%)$ & 25 & \\
\hline MDSCC & $0(0 \%)$ & $0(0 \%)$ & $3(15 \%)$ & $13(65 \%)$ & $4(20 \%)$ & 20 & \\
\hline PDSCC & $2(28.6 \%)$ & \begin{tabular}{|l|}
$2(28.6 \%)$ \\
\end{tabular} & $1(14.3 \%)$ & $1(14.3 \%)$ & \begin{tabular}{|l|}
$1(14.3 \%)$ \\
\end{tabular} & 7 & \\
\hline $\begin{array}{l}\text { Normal } \\
\text { Mucosa }\end{array}$ & $0(0) \%$ & $3(50 \%)$ & $3(50 \%)$ & $0(0) \%$ & $0(0) \%$ & 6 & \\
\hline Total & $2(3.4 \%)$ & \begin{tabular}{|l}
$9(15.5 \%)$ \\
\end{tabular} & $19(32.8 \%)$ & $22(37.9 \%)$ & \begin{tabular}{|l|}
$6(10.3 \%)$ \\
\end{tabular} & 58 & \\
\hline \multicolumn{8}{|c|}{$\begin{array}{l}\text { Table 2. Cross-Tabulation for Percentage of p63-Positive } \\
\text { Cells and Grade of Squamous Cell Carcinoma }\end{array}$} \\
\hline
\end{tabular}

\begin{tabular}{|c|c|c|c|c|c|c|}
\hline Grade & No. of Cases & Mean & S.D. $(\sigma)$ & Min & Max & \\
\hline WDSCC & 25 & 5.56 & 2.238 & 2 & 9 & \multirow{4}{*}{$\begin{array}{c}\mathrm{F}=9.57 \\
\mathrm{p}<0.001 \\
\text { Very highly } \\
\text { significant }\end{array}$} \\
\hline MDSCC & 20 & 8.55 & 2.564 & 4 & 12 & \\
\hline PDSCC & 7 & 4.27 & 4.786 & 0 & 12 & \\
\hline Normal mucosa & 6 & 3.00 & 1.265 & 1 & 4 & \\
\hline \multicolumn{7}{|c|}{$\begin{array}{l}\text { Table 3. Cross-Tabulation for IR (Immunoreactive) Score } \\
\text { and Grade of Squamous Cell Carcinoma }\end{array}$} \\
\hline
\end{tabular}

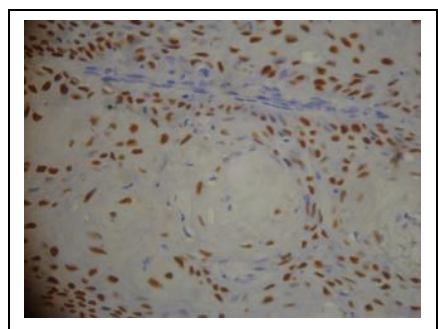

Figure 1.

Photomicrograph Showing p63 Immunohistochemical Staining in Well Differentiated Squamous Cell Carcinoma (40x)

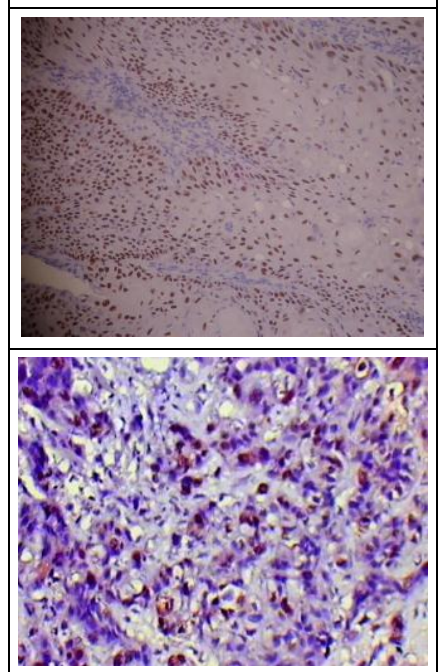

Figure 2.

Photomicrograph Showing 063 Immunohistochemical Staining in Moderately Differentiated Squamous Cell Carcinoma (10X)

Figure 3.

Photomicrograph Showing p63 Immunohistochemical Staining in Poorly Differentiated Squamous Cell Carcinoma (40X) 
Our study included 6 cases of tongue carcinoma which consisted of 2 well differentiated OSCC cases, 3 cases of moderately differentiated and 1 case of poorly differentiated OSCC. All 6 cases had lymph node involvement at initial presentation, 2 of the patients gave history of alcohol habits. These findings are in agreement with other studies which have mentioned tongue carcinoma as an aggressive entity with poor prognosis. ${ }^{17}$

\section{DISCUSSION}

In our study, a highly significant association $(\mathrm{p}=0.003)$ between intensity of p63 and different grades of OSCC was observed (Refer Table 1) A very highly significant association $(p<0.001)$ between percentage of cells stained for p63 and different grades of OSCC was observed (Table 2). There was a very highly significant association $(\mathrm{p}<0.001)$ found between IR score for p63 staining and different grades of OSCC (Table 3).

Normal mucosa showed consistency in the number of cells stained which included basal and parabasal cells. This is in agreement with most of the previous studies. When WDSCC and normal mucosa were compared, the differences were non-significant for both intensity and percentage of cells stained. Between MDSCC and normal mucosa, very highly significant results were obtained with regard to percentage of cells stained. Significant differences were observed in IHC intensity scores between MDSCC and normal mucosa.

In a study by Patel et al, all the cases showed positive expression for p63 with statistically significant differences in different grades of OSCC. ${ }^{18}$ In our study, all cases of well differentiated and moderately differentiated oral squamous cell carcinoma showed positive expression for p63. Among the WDSCC cases, $4 \%$ showed low intensity of staining, $44 \%$ showed moderate staining and $52 \%$ showed strong staining. Also, the outer peripheral cells with intact nucleus showed positivity, while inner keratinized cells were negative (Fig. 1). This phenomenon is reflected in the percentage of cells stained which is less in WDSCC as compared to MDSCC or PDSCCC. In case of MDSCC, $75 \%$ cases showed a strong staining intensity pattern while, the rest showed moderate staining (Fig. 2). Thus, the staining intensity increased with the increasing grade in the present study. This is in concordance with Matsubara et $\mathrm{al}^{10}$ as well as Lo Muzio et al $^{19}$ who reported a positive correlation between the histologic grade and $\Delta \mathrm{N}$ p63 positivity in HNSCCC. Chen et al reported all SCC cases in their study as positive for p63 marker $2036 / 38$ cases showed positive p63 expression in study by Choi et al. ${ }^{21}$ On the other hand, although p63 positivity was seen in $87.8 \%$ of the tumours in De Oliviera et al study, they concluded that neither the staining intensity pattern nor quantity of the stained cells was useful to distinguish significantly the degree of differentiation of the studied lesions. ${ }^{22}$

In our study, we found that poorly differentiated squamous cell carcinoma showed extreme variations, 2 cases(28.6\%) were negative for p63 expression, 1 case $(14.3 \%)$ each showed mild and moderate p63 expression, while, $43 \%$ (3 cases) showed high intensity of staining(Fig. 3). These findings are in concordance with
Shetty et al who have also reported negative results in their study regarding p63 expression in 30\% cases of PDSCC. They have attributed these findings to dedifferentiation of the tumour cells leading to absence of p63 expression. ${ }^{23}$ Somewhat similar findings have been reported for PDSCC in Oliviera et al study where, $61.5 \%(8 / 17)$ of PDSCC cases were negative for $\mathrm{p} 63,4 / 16$ showed mild staining, 4/16 moderate, and only 1 case showed high intensity staining. ${ }^{22}$

Wide deviation was observed in PDSCC for both Intensity and percentage of staining, the IR score ranging from 0 to 12 . While some cases showed a strong expression, few cases were totally negative for p63 expression, similar to an all or none phenomenon. Anaplastic carcinomas are difficult to differentiate from mesenchymal tumours, melanomas and lymphomas. p63 can be a good tool for identifying epithelial tumours in such cases, especially spindle cell carcinomas from other spindle cell tumours. More studies with bigger sample size might give conclusive results on these interesting findings.

Many of the cases were associated with betel quid chewing with tobacco, which is a common and acceptable social habit in the native population. This assumes significance since smoking has been banned in public spaces and is seeing a decreasing trend.

\section{CONCLUSIONS}

There are statistically significant differences in the intensity and percentage of cells stained for p63 marker. Clinicopathologic study of the subject patients of oral cancer in coastal Karnataka and Kasaragod confirms that most of the patients have a history of tobacco chewing with/without arecanut. Also, there is a trend towards relatively younger people ( $4^{\text {th }}$ and $5^{\text {th }}$ decade) getting affected by oral cancer. Studies indicate that $\Delta \mathrm{Np} 63$ is the major isoform detected in the immunohistochemistry of tumour cells in Squamous Cell Carcinomas. Presence of $\Delta \mathrm{Np} 63$ in the tumour tissue indicates the aggressiveness of the tumour, as $\Delta \mathrm{Np} 63$ promotes proliferation, anti-apoptotic effects and stem cell properties. Thus, p63 can serve as a useful aid in patient follow-up and screening. Also, recurrence of oral cancer can be monitored by the marker. p63 can be a useful marker in diagnosis of poorly differentiated or undifferentiated squamous cell carcinomas as it is an epithelial stem cell marker and can differentiate epithelial cells from mesenchymal origin cells. Studies have shown that $\Delta \mathrm{Np} 63$ expression is directly correlated with the clinical response to cisplatin in patients with HNSCC. Good response has been seen in HNSCC patients with higher $\triangle \mathrm{Np63}$ expressions to cisplatin chemotherapy. The reason for this observation is that Cisplatin targets $\Delta \mathrm{Np} 63$ which acts as a critical survival factor for the tumour cells. ${ }^{24}$ This observation can help in deciding the modalities of treatment planning for oral squamous cell carcinoma patients. However, more in-depth studies in collaboration with the clinicians are needed for confirming the same observations. Thus, p63 can help in determining the tumour behavior in different grades of oral squamous cell carcinoma. 


\section{REFERENCES}

[1] Das RK, Venkataraghavan V, Sheet D, et al. Evaluation of p63 expression in oral sub-mucous fibrosis. Proceedings of 2010 International Conference on Systems in Medicine and Biology 16-18 Dec 2010, IIT Kharagpur, India: IEEE 2010: p. 166-71.

[2] Kaur J, Srivastava A, Ralhan R. Overexpression of p53 protein in betel and tobacco-related human oral dysplasia and squamous cell carcinoma in India. Int J Cancer 1994;58(3):340-5.

[3] Lam L, Logan RM, Luke C, et al. Retrospective study of survival and treatment pattern in a cohort of patients with oral and oropharyngeal tongue cancers from 1987 to 2004. Oral Oncol 2007;43(2):150-8.

[4] Ramasubramaniam A, Ramani P, Sherlin HJ, et al. Immunohistochemical evaluation of oral epithelial dysplasia using cyclin-D1, p27 and p63 expression as predictors of malignant transformation. J Nat Sci Biol and Med 2013;4(2):349-58.

[5] Yu YH, Morales J, Feng L, et al. CD147 and Ki-67 overexpression confers poor prognosis in squamous cell carcinoma of tongue. Oral Surg Oral Med Oral Pathol Oral Radiol 2015;119(5):553-65.

[6] Shah RB, Zhou M, LeBlanc M, et al. Comparison of the basal cell-specific markers, 34 [beta] e12 and p63 in the diagnosis of prostate cancer. Am J Surg Path 2002;26(9):1161-8.

[7] Hibi K, Trink B, Patturajan M, et al. AIS is an oncogene amplified in squamous cell carcinoma. Proc Natl Acad Sci USA 2000;97(10):5462-7.

[8] Mills AA, Zheng B, Wang XJ, et al. p63 is a p53 homologue required for limb and epidermal morphogenesis. Nature 1999;398(6729):708-13.

[9] Yang A, Schwitzer R, Sun D, et al. p63 is essential for regenerative proliferation in limb, craniofacial and epithelial development. Nature 1999;398(6729):714-8.

[10] Matsubara R, Kawano S, Kiyosue T, et al. Increased $\Delta \mathrm{Np} 63$ expression is predictive of malignant transformation in Epithelial dysplasia and poor prognosis in oral squamous cell carcinoma. Int J Oncology 2011;39(6):1391-9.

[11] Nylander K, Coates P, Hall PA. Characterization of expression pattern of $\mathrm{p} 63 \alpha$ and $\Delta \mathrm{Np} 63 \alpha$ in benign and malignant oral epithelial lesions. Int J Cancer 2000;87(3):368-72.
[12] Boldrup L, Coates PJ, Laurell G, et al. Differences in p63 expression in SCCHN tumours of different subsites within the oral cavity. Oral Oncol 2011;47(9):861-5.

[13] Guo X, Keyes WM, Papazoglu C, et al. TAp63 induces senescence and suppresses tumourigenesis in vivo. Nat Cell Biol 2009;11(12):1451-7.

[14] Rocco JW, Leong CO, Kuperwasser N, et al. p63 mediates survival in squamous cell carcinoma by suppression of p73-dependent apoptosis. Cancer Cell 2006;9(1):45-56.

[15] Kovesi G, Szende B. Prognostic value of cyclin D1, p27 and p63 in oral leukoplakia. J Oral Pathol Med 2006;35(5):274-7.

[16] Barnes L, Eweson JW, Reichert P. WHO classification of tumours. Lyon: IARC Press 2005.

[17] Loljung L, Coates PJ, Nekulova M, et al. High expression of p63 correlate to poor prognosis in squamous cell carcinoma of tongue. J Oral Pathol Med 2014;43(1):14-9.

[18] Patel SB, Manjunatha BS, Shah V, et al. Immunohistochemical evaluation of p63, cyclin D1 in Oral squamous cell carcinoma and leukoplakia. J Korean Assoc Oral Maxillofac Surg 2017;43(5):324-30.

[19] Lo Muzio L, Santarelli A, Caltabiano R, et al. p63 overexpression associates with poor prognosis in head and neck squamous cell carcinoma. Hum Pathol 2005;36(2):187-94.

[20] Chen YK, Huse SS, Lin LM. Differential expression of p53, p63 and p73 proteins in human buccal squamous- cell carcinoma. Clinical Otolaryngol Allied Sci 2003;28(5):451-5.

[21] Choi HR, Batsakis JG, Zhan F, et al. Differential expression of p53 gene family members p63 and p73 in head and neck squamous tumourigenesis. Hum Pathol 2002;33(2):158-64.

[22] De Oliviera LR, Ribeiro-Silva A, Zucoloto S. Prognostic impact of p53 and p63 immunoexpression in Oral squamous cell carcinoma. J Oral Pathol Med 2007;36(4):191-7.

[23] Shetty SS, Krishnapillai R, Prabhu S. Assessment and comparison of p53 and p63 expression in Oral Epithelial Dysplasia and Squamous cell carcinoma. SRM J Research in Dental Sciences 2014;5(3):149-54.

[24] Leong CO, Vidnovic N, De Young MP, et al. The p63/p73 network mediates chemosensitivity to cisplatin in a biologically defined subset of primary breast cancers. J Clin Invest 2007;117(5):1370-80. 